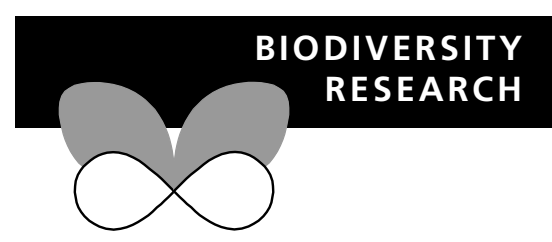

\title{
The role of demography and climatic events in shaping the phylogeography of Amazona aestiva (Psittaciformes, Aves) and definition of management units for conservation
}

\author{
Renato Caparroz ${ }^{1 \star}$, Gláucia Helena Fernandes Seixas ${ }^{2}$, Igor Berkunsky ${ }^{3}$ and \\ Rosane Garcia Collevatti ${ }^{1}$
}

\begin{abstract}
${ }^{1}$ Pós-graduação em Ciências Genômicas e Biotecnologia, Universidade Católica de Brasília, Campus II SGAN 916 Norte, Av. W5, 70790-160, Brasília, DF, Brazil, ${ }^{2}$ Projeto Papagaio-verdadeiro, Fundação Neotrópica do Brazil, Bonito, Mato Grosso do Sul, Brazil, ${ }^{3}$ Facultad de Ciencias Exactas y Naturales, Universidad de Buenos Aires, Buenos Aires, Argentina
\end{abstract}

${ }^{*}$ Correspondence: Renato Caparroz,

E-mail: renatocz@ucb.br; rosanegc@pos.ucb.br

\begin{abstract}
Aim The blue-fronted amazon (Amazona aestiva) is a widely distributed Neotropical parrot with two recognized sub-species, which are mainly characterized by the colour of the shoulder. We explored mitochondrial DNA variability to determine how demographic processes and historical climatic fluctuations may have contributed to phylogeographical pattern and morphological variation of A. aestiva, and how this information could be useful to understand the evolutionary relationship of this species and the Amazona ochrocephala complex and to determine management units for conservation purposes.
\end{abstract}

Location Brazil and north-eastern Argentina.

Methods We analysed a fragment of COI gene of 78 A. aestiva and 27 A. ochrocephala. We computed a median-joining network, and the population structure of A. aestiva populations was assessed using a hierarchical analysis of nucleotide diversity. The mismatch distribution, Fu's $F_{\mathrm{s}}$-test of neutrality and $R^{2}$ test were used to detect past population expansion.

Results All A. aestiva haplotypes and A. ochrocephala subspecies from north-eastern and southern South America were recovered within the South American clade. Hierarchical analysis of nucleotide diversity of $A$. aestiva populations detected two geographical groups as obtained by median-joining network. These two A. aestiva groups showed evidence of a recent population expansion. The time of populations splitting estimated corresponding to the Middle Pleistocene.

Main conclusions The two A. aestiva genetic groups identified in our analyses agree with the morphological variation, corresponding to named subspecies. These two A. aestiva groups have undergone a recent population expansion, with low gene flow between them. The expansion of savannah areas may have contributed to the population expansion of these two groups. We concluded that introgression after isolated diversification may better explain haplotype sharing between A. aestiva and A. ochrocephala subspecies. We suggest that management and conservation strategies should consider these two A. aestiva groups (or subspecies) as different management units and should maintain viable populations of these two management units.

\section{Keywords}

Amazona aestiva, Amazona ochrocephala, conservation, mtDNA, phylogeography, Pleistocene. 


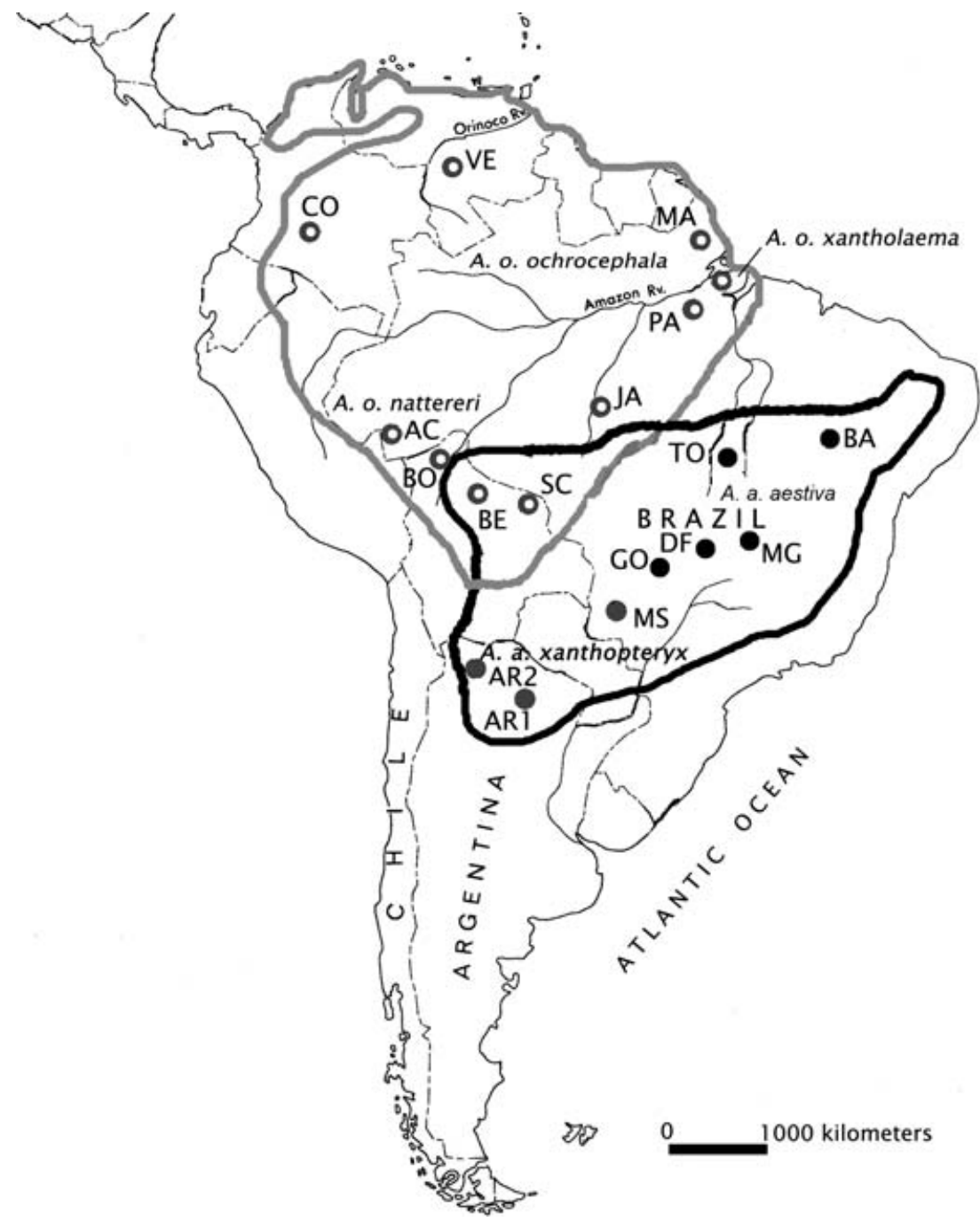

Figure 1 Collection localities of samples included in this study. Two letter codes correspond to localities specified in Table 1. The grey line delimits the distribution of Amazona ochrocephala. The black line delimits the distribution of Amazona aestiva. Distribution of subspecies is indicated with their corresponding names. The geometric forms correspond to group I (black) and group II (grey) identified in the phylogeographical analysis of A. aestiva.

\section{INTRODUCTION}

Phylogeographical studies have been powerful in elucidating patterns of gene flow, hybridization, historical range fragmentation and expansion, and speciation among many bird species (Avise, 2000; Newton, 2003; references therein). They may also provide information to understand the influence of historical events, such as Pleistocene climatic shifts, on the genetic and phenotypic variation of species. Pleistocene conditions may have played an important role both in initiating major phylogeographical division within bird species, and in completing speciation (Avise \&Walker, 1998). Because of their patterns of diversity and distribution (Forshaw, 1989; Juniper \& Parr, 1998), the study of evolutionary history of Neotropical parrots may be particularly informative for understanding the biogeographical history of the Neotropics.

The blue-fronted amazon (Amazona aestiva) is a widely distributed Neotropical parrot, with an estimated global area of occurrence of 4.2 million $\mathrm{km}^{2}$ (Collar, 1997), ranging from dry tropical to subtropical vegetation, mainly in the Chaco in Argentina and in the Cerrado (savannah vegetation) in Brazil (Collar, 1997). This species includes two recognized subspecies, which are characterized mainly by the colour of the shoulder: Amazona aestiva aestiva has a red shoulder and Amazona aestiva xanthopteryx has a yellow shoulder with some red markings (Darrieu, 1983; Forshaw, 1989). The first subspecies occurs in eastern Brazil from eastern Pará to the South of Paraná and south-eastern Mato Grosso. The latter ranges from north-eastern Bolivia, and south-western Mato Grosso, Brazil, to southern Paraguay and northern Argentina (Darrieu, 1983; Forshaw, 1989). An overlap in the distribution of both subspecies may occur in Central Mato Grosso do Sul, Brazil, where the amazons have shoulders with a mix of red/yellow feathers (Darrieu, 1983) (Fig. 1). This species provides a good model to evaluate the role of Pleistocene climate cycles in driving differentiation in Neotropical bird species because of its broad geographical distribution in South America's open areas (Cerrado and Chaco) and morphological variation. Climatic fluctuation may have caused cycles of savannah vegetation contraction and expansion in South America (Martinson et al., 1987; Potts \& Behrensmeyer, 1992; Haberle, 1997), which may have in turn had important effects on the phylogeographical pattern of this species. 
Recent molecular studies indicate that $A$. aestiva comprises a paraphyletic group with the Amazona ochrocephala complex (Eberhard \& Bermingham, 2004; Russello \& Amato, 2004; Ribas et al., 2007). These findings strongly suggest that the current taxonomy of these species is in need of revision. The A. ochrocephala complex is distributed in lowlands from Mexico to the Amazon basin and is considered by some authors as comprising only one species with nine (Forshaw, 1989) or ten (Collar, 1997) subspecies, defined on the basis of the distribution of yellow on the head and thighs, and on the colour variation of the bill and foot. The primary character that distinguishes A. ochrocephala species from A. aestiva is the black bill on the latter (Forshaw, 1989; L. F. Silveira, pers. comm.). These previous phylogenetic studies included two or three samples of A. aestiva without information of its geographical origin (Eberhard \& Bermingham, 2004; Russello \& Amato, 2004, respectively), or few samples of A. aestiva from three localities in Brazil (Ribas et al., 2007). Thus, a detailed population analysis of $A$. aestiva could be helpful to understand the evolutionary relationship between this species and A. ochrocephala complex, and to clarify the taxonomy. Furthermore, A. aestiva and the South American subspecies of the A. ochrocephala complex (expect Amazona oratrix) are considered taxa of Least Concern by the IUCN (IUCN, 2006); however, population declines have been observed in some regions (Bucher \& Martella, 1988; Collar \& Juniper, 1988). A good correspondence between phylogenetic history and taxonomy can reveal biogeographical patterns, and this information is important for conservation planning.

In the present study we explored mitochondrial DNA variability to investigate how demographic processes and historical climatic fluctuations may have contributed to phylogeographical pattern and morphological variation of both A. aestiva subspecies. We examined how this evidence could be helpful to understand the evolutionary relationship of this species and the A. ochrocephala complex, and discuss how our results can clarify the taxonomy and help conservation of these species.

\section{METHODS}

\section{Sample collection and DNA extraction}

During the breeding seasons of 2000 and 2006, 78 wild blue-fronted amazon nestlings were sampled at six localities in Central Brazil and two localities in northern Argentina (Fig. 1, Appendix S1; Supplementary Material). To avoid pseudoreplication, the analyses were carried out using only one sample per nest. Samples included representatives from 59 A. a. aestiva and 19 A. a. xanthopteryx. Blood $(0.1 \mathrm{~mL})$ from the brachial vein was collected from each individual and preserved in $100 \%$ ethyl alcohol at room temperature.

Template DNA was extracted from blood by incubation overnight at $37^{\circ} \mathrm{C}$ in a solution containing $0.1 \%$ sodium dodecyl sulfate, $100 \mathrm{~mm}$ Tris- $\mathrm{HCl}$ ( $\mathrm{pH} 8.0$ ), $10 \mathrm{~mm} \mathrm{NaCl}, 10 \mathrm{~mm}$ ethylenediaminetetraacetic acid and $0.4 \mathrm{mg}$ of proteinase $\mathrm{K}$, followed by purification using the standard phenol-chloroform-isoamyl alcohol procedure (Bruford et al., 1992).

\section{Mitochondrial DNA sequencing}

A 506 base pair fragment of cytochrome oxidase I gene (COI) was amplified using the primers COIa and COIf (Palumbi, 1996). Polymerase chain reaction amplifications were performed in $10 \mu \mathrm{L}$ reactions with $20-50 \mathrm{ng}$ of DNA, $1 \times$ reaction buffer (10 mm of Tris- $\mathrm{HCl} \mathrm{pH} \mathrm{8.3,} 50 \mathrm{~mm}$ of $\mathrm{KCl}, 1.5 \mathrm{~mm}$ of $\mathrm{MgCl}_{2}$ ) $200 \mu_{\mathrm{M}}$ of each deoxynucleotide triphosphate, $0.8 \mu_{\mathrm{M}}$ of each primer, and 0.5 unit of Taq polymerase (Phoneutria, BR) in a PE 9700 thermal cycler (Applied Biosystems, CA). Each reaction consisted of an initial step of $95^{\circ} \mathrm{C}$ for $7 \mathrm{~min}$., followed by 35 cycles of $95^{\circ} \mathrm{C}(1 \mathrm{~min}),. 53{ }^{\circ} \mathrm{C}(40 \mathrm{~s}), 72^{\circ} \mathrm{C}(40 \mathrm{~s})$, and a final extension of $72^{\circ} \mathrm{C}$ for $10 \mathrm{~min}$. Both DNA strands were sequenced using the DYEnamic ET Terminator kit (GE Healthcare, Sweden) following the manufacturer's instructions. Sequencing products were loaded in $5 \%$ polyacrylamide denaturing gels on an ABI 377 automated sequencer (Applied Biosystems, CA) and checked and edited using SEQScape ver. 2.1 (Applied Biosystems, CA). The sequences were aligned using the CLUSTALW ver. 1.4 (Thompson et al., 1997).

\section{Sequence variation and population analysis}

Nucleotide $(\pi ;$ Nei, 1987) and haplotype ( $h$; Nei, 1987$)$ diversity were estimated for each $A$. aestiva population using the software ArLequin ver. 2.0 (Schneider et al., 2000). Phylogeographical pattern of A. aestiva was assessed by computing a median-joining network using the algorithm described by Bandelt et al. (1999) and implemented in the NeTwork ver. 4.1.1.0 (Fluxus Technology Ltd). To evaluate the relationship between $A$. aestiva and A. ochrocephala we also analysed homologous sequences of 27 individuals of $A$. ochrocephala, which were obtained from GenBank (Fig. 1, Appendix S1; Supporting Information).

Population structure in A. aestiva was tested using a hierarchical analysis of nucleotide diversity implemented in NucLeodiv (Holsinger \& Mason-Gamer, 1996). This method uses pairwise estimates of $\mathrm{g}_{\mathrm{ST}}$, the unbiased estimator of the proportion of nucleotide diversity between populations, between all pairs of populations to construct a dendrogram and identify patterns of hierarchical population structure in the data. This analysis allows any pattern among populations to emerge naturally from the data, rather than using an a priori hypothesis about the structure. Statistical significance of $g_{S T}$ values at each node was tested by creating a null distribution of values generated by random resampling and comparing the observed value with this null distribution (Holsinger \& Mason-Gamer, 1996).

\section{Demographic history of $A$. aestiva}

Demographic analysis was performed based on the results of the genetic structure analysis (Fig. 3). The 78 sampled individuals were separated into two groups: group I - north-eastern (46 individuals from BA, MG, TO, DF and GO), and group II south-western (32 individuals from MS, AR1 and AR2). To evaluate whether the blue-fronted amazon groups are at demographic equilibrium, the observed and expected mismatch 
distribution under a sudden expansion model was plotted using the DNASP ver. 4.10.9 (Rozas et al., 2003). Fu's $F_{s}$-test of neutrality (Fu, 1997) and $R^{2}$ test (Ramos-Onsins \& Rozas, 2002) were used to detect past population expansion with DNASP ver. 4.10.9.

A coalescent model was used to distinguish the contribution of isolation and migration to the observed patterns of genetic divergence between those two groups, and better understand the demographic history of A. aestiva. The following population parameters where estimated with the IM software (Hey \& Nielsen, 2004): $\theta_{1}$ (effective number of individuals in population 1), $\theta_{2}$ (effective number of individuals in population 2) and $\theta_{\mathrm{A}}$ (effective number of individuals in the ancestral population at the time of population divergence), $m$ ( $m_{1}$ plus $m_{2}$, the effective number of migrants per generation), $t$ (time of population divergence) and the expected time to the most recent common ancestor (TMRCA). The posterior probability densities of the parameters were generated by simulating a Markov chain having a stationary distribution. Individual simulations were run for 10 million updates, with a burn-in period of 500,000 steps excluded from the subsequent analyses. We used a procedure for swapping among multiple heated chains to ensure that the distributions obtained actually reflected the stationary distributions. Metropolis-coupling runs used ten coupled chains that varied over a range of heating values $\left(\mathrm{g}_{1}=0.817\right.$ and $\left.\mathrm{g}_{2}=0.7\right)$. The modal values of the resulting distributions were considered as the estimates of the parameters. To estimate each parameter we considered only the $90 \%$ highest posterior density intervals, which are the boundaries of the shortest span that includes $90 \%$ of the probability density of a parameter. To estimate time of splitting and population effective size we assumed a divergence rate of $2 \%$ per million years for mtDNA, or $2.53 \times 10^{-5}$ substitutions per locus per lineage per generation, and a generation time of 5 years. The calibration of molecular clock used here was originally obtained from mitochondrial DNA restriction fragment-length polymorphism data from chimpanzees and humans (Brown et al., 1979) and was supported by similar rates obtained for other bird species using fossil records (Shields \& Wilson, 1987; Randi, 1996) and other vertebrates (Wilson et al., 1985).

\section{RESULTS}

\section{Sequence variation}

Among the A. aestiva individuals sequenced, 16 of the 506 sites (3.2\%) were polymorphic. With the exception of site 496 , all polymorphic sites were at third codon positions and resulted in synonymous amino-acid substitutions. The substitution at site 496 in haplotype H11 resulted in the substitution of a valine by an isoleucine. No indels or stop codons were found and variation within the sequences included 19 transitions and only one transversion. The average uncorrected pairwise sequence distance among all $A$. aestiva sequences was $0.45 \%$ (range of $0.00-1.27 \%$ ). Comparing $A$. aestiva and $A$. ochrocephala sequences, 37 polymorphic sites $(7.3 \%)$ were found within the $506 \mathrm{bp}$ fragment. The average uncorrected pairwise sequence distance between A. aestiva and A. ochrocephala samples was $0.84 \%$ (range $0.00-3.75 \%$ ).
Table 1 The blue-fronted amazon population diversity based on the sequence of mtDNA COI gene. $\mathrm{N}$, sample size; $\mathrm{H}$, number of haplotypes; $\pi \pm \mathrm{SD}$, nucleotide diversity \pm standard deviation; $h$, haplotype diversity.

\begin{tabular}{lrlll}
\hline Population locality (acronym) & $\mathrm{N}$ & $\mathrm{H}$ & $\pi \pm \mathrm{SD}$ & $h$ \\
\hline Bahia, Brazil (BA) & 7 & 3 & $0.002 \pm 0.002$ & 0.67 \\
Tocantins, Brazil (TO) & 14 & 2 & $0.001 \pm 0.001$ & 0.14 \\
Minas Gerais, Brazil (MG) & 10 & 3 & $0.002 \pm 0.002$ & 0.67 \\
Distrito Federal, Brazil (DF) & 12 & 1 & 0.000 & 0.00 \\
Goiás, Brazil (GO) & 3 & 1 & 0.000 & 0.00 \\
Mato Grosso do Sul (MS) & 13 & 4 & $0.004 \pm 0.002$ & 0.78 \\
Provincia del Chaco, Argentina (AR1) & 14 & 4 & $0.001 \pm 0.001$ & 0.49 \\
Província del Jujuy, Argentina (AR2) & 5 & 2 & $0.001 \pm 0.001$ & 0.60 \\
Total & 78 & & & \\
\end{tabular}

The overall value of nucleotide diversity per site across all A. aestiva samples was $0.004 \pm 0.003$ (Table 1 ). Nucleotide diversity values were lower for DF and GO $(\pi=0.0)$ and higher for MS $(\pi=0.004)$. The overall value of haplotype diversity across all A. aestiva samples was 0.75 (range $0.0-0.78$ ). Haplotype diversity value of the MS $(h=0.78)$ was higher than in the other localities.

\section{Population analysis}

Median-joining network recovered three primary clades: Northern South American (NSA), Central America (CA) and South American (SA) (Fig. 2). NSA clade was comprised by A. $o$. ochrocephala from Colombia and Venezuela, whereas CA was comprised by A. ochrocephala subspecies from Central America. Thirteen haplotypes were found among the $78 \mathrm{~A}$. aestiva sampled and most of them were restricted to only one population, with exception of the haplotypes $\mathrm{H} 01, \mathrm{H} 06$ and $\mathrm{H} 08$, which were shared by four, two, and six populations, respectively (Fig. 2). All A. aestiva haplotypes and A. ochrocephala subspecies from north-eastern and southern South America were recovered within the SA clade, which was divided into two primary groups: group I - comprising almost exclusively by A. aestiva haplotypes found in the north-eastern localities (BA, MG, TO, DF and GO), all A. o. xantholaema samples and one A. o. ochrocephala from Santa Cruz (western Bolivia); and group II - composed almost exclusively by the $A$. aestiva haplotypes found in the southwestern localities (MS, AR1 and AR2), A. o. ochrocephala from Altamira and Macapa (north-eastern Brazil), and A. o. nattereri from several localities in Brazil and Bolivia. A. aestiva and $A$. ochrocephala shared the two haplotypes ( $\mathrm{H} 01$ and $\mathrm{H} 08)$ that were most frequently shared within A. aestiva.

Hierarchical analysis of nucleotide diversity of $A$. aestiva populations (Fig. 3) detected the same geographical groups as obtained by median-joining network. A major division was observed between the north-eastern localities (BA, TO, MG, DF and GO, group I) and the southwestern (MS, AR1 and AR2, group II), but within group I a significant differentiation was identified between the BA and the remaining north-eastern localities. 


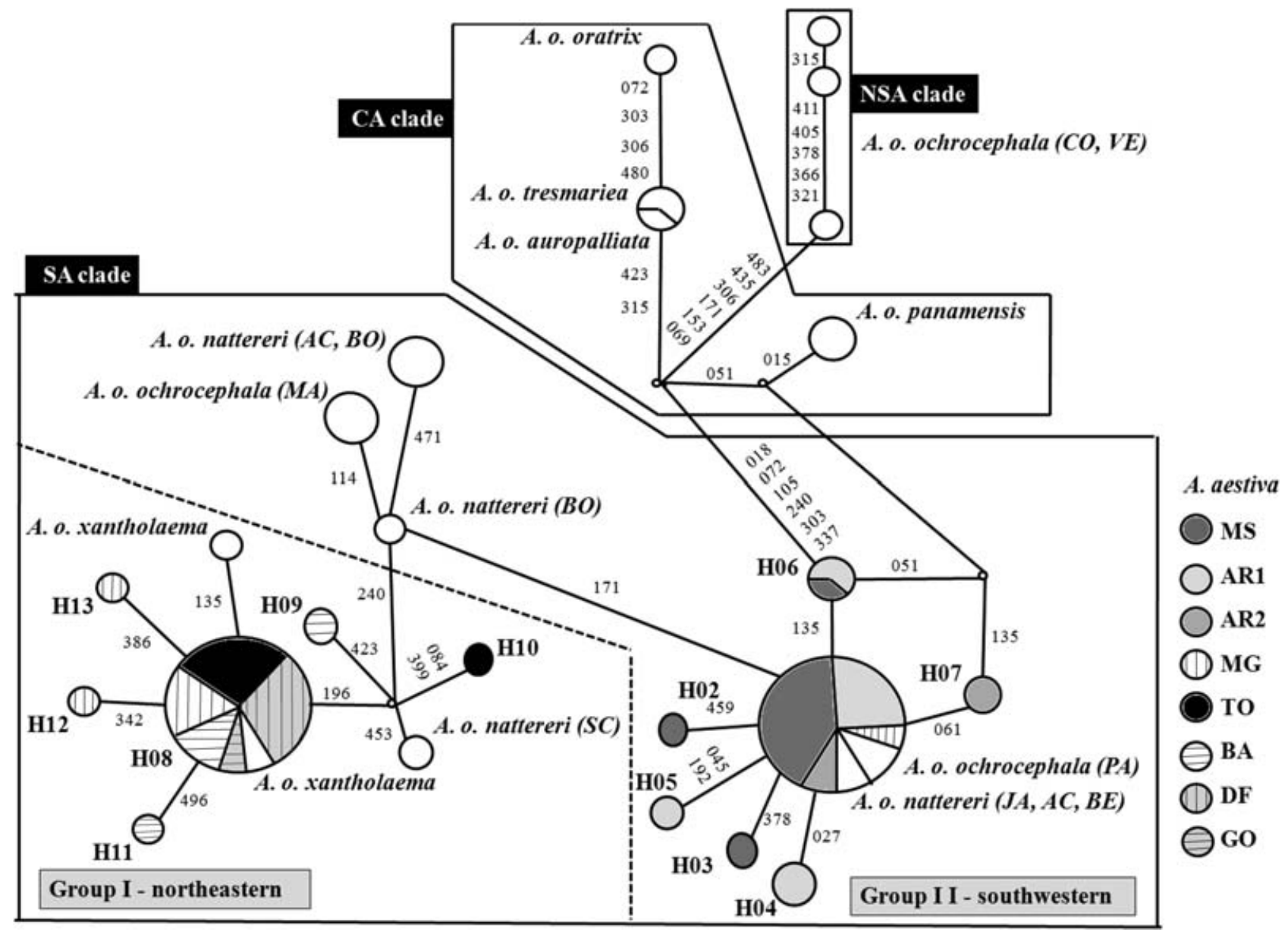

Figure 2 Relationships among the 78 Amazona aestiva and 27 A. ochrocephala based on the median-joining network of 506 bp of mitochondrial DNA COI sequences. The number on the line connecting haplotypes indicates the number of variable sites between them. Sizes of circles are proportional to the haplotype frequency. For location abbreviations, see Appendix S1 (Supplementary Material).

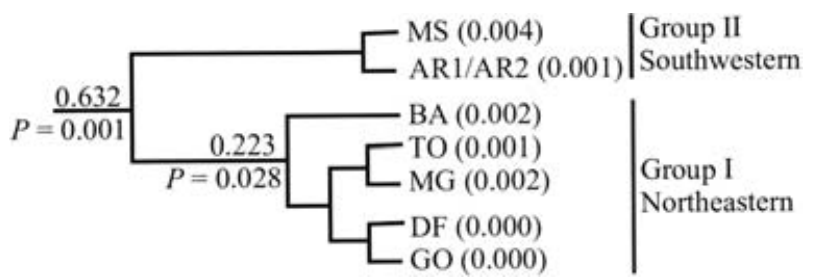

Figure 3 Genetic relationships among the seven populations sampled as inferred from the hierarchical analysis of nucleotide diversity (two letter codes correspond to localities specified in Table 1). The significant values of $\mathrm{g}_{\mathrm{ST}}$ are shown and represent the proportion of the total genetic diversity within the cluster determined by a node that is partitioned between sister locations. The probability of observing higher values of $\mathrm{g}_{\mathrm{ST}}$ by chance is also shown. These probabilities were obtained considering a null distribution of $\mathrm{g}_{\mathrm{ST}}$ values from 1.000 replicates of random resampling of the haplotypes found in the compared populations.

\section{Demographic history}

The two A. aestiva groups identified in previous analyses showed evidence of a recent population expansion, with one haplotype with high frequency and several other closely related haplotypes with low frequencies (Fig. 2). The mismatch distributions for these two groups also fit the expansion model curve (Fig. 4). Further evidence for population expansion in these two groups was provided by the results of Fu's neutrality test, which showed significant negative values $(F=-4.87, P=0.002$ for group I; $F=-4.24, P=0.006$ for group II). The $R^{2}$ statistic was also significant for both groups $\left(R^{2}=0.056, P=0.040\right.$, for group I; $R^{2}=0.058, P=0.002$, for group II), which is consistent with a recent population expansion.

Maximum-likelihood values of $\theta_{\mathrm{A}}, \theta_{1}$, and $\theta_{2}$ estimated from the coalescence analysis for the ancestral group I and group II comparison using IM were $0.01,7.98$ and 5.74, respectively (Table 2). Considering the standard molecular clock calibration of $2 \%$ per Ma, these values correspond to a population effective size of females of 99, 56,719 and 78,854 for ancestral, group I and group II populations, respectively. These estimated values also suggest that the two groups underwent population expansion. 
Group I - northeastern

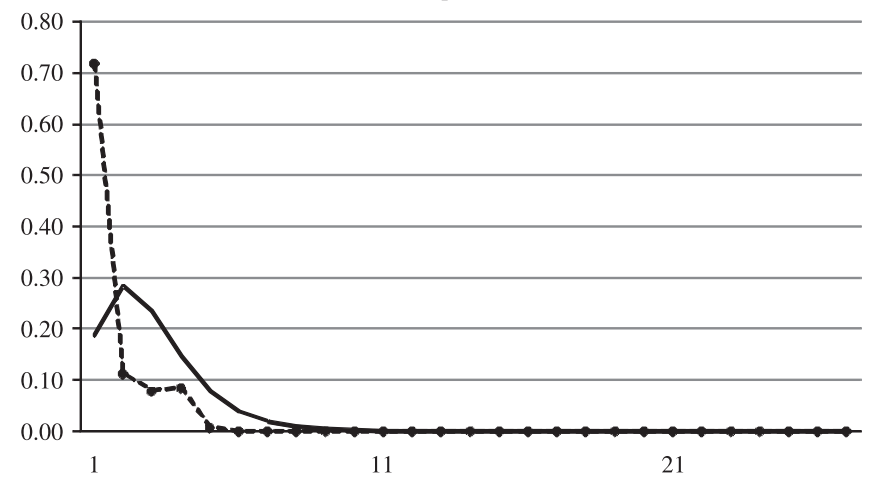

Group II - southwestern

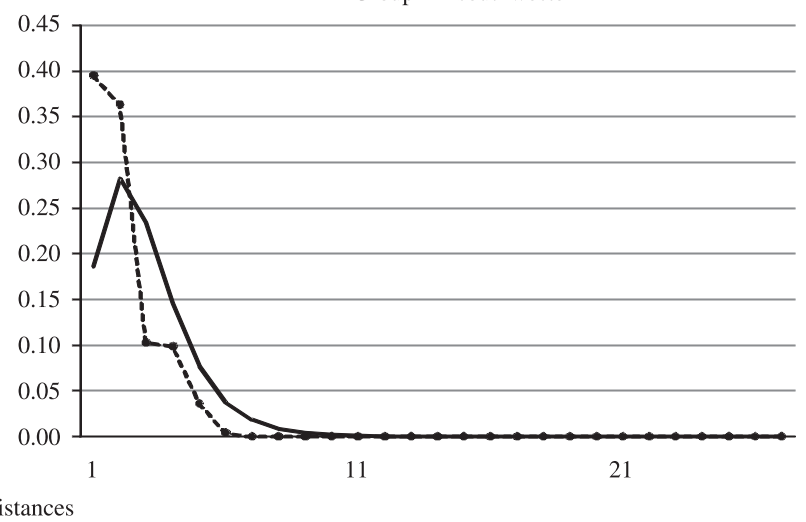

Figure 4 Mismatch distributions of Amazona aestiva group I and II identified by phylogeographical analysis. Dashed lines indicate the observed distribution of pairwise differences and solid lines show the expected distribution under a model of sudden expansion (Rogers \& Harpending, 1992).

Table 2 Population demographic parameters based on coalescent estimates (MLE) on mtDNA assuming the splitting of south-western (group II) and north-eastern (group I) A. aestiva populations. HPD is the $90 \%$ highest posterior density interval of demographic parameters.

\begin{tabular}{|c|c|c|c|c|c|c|c|c|c|c|c|c|}
\hline & \multirow[b]{2}{*}{$\theta_{\text {group II }}$} & \multirow[b]{2}{*}{$\theta_{\text {group I }}$} & \multirow[b]{2}{*}{$\theta_{\mathrm{A}}$} & \multirow[b]{2}{*}{$m_{\text {group II }}$} & \multirow[b]{2}{*}{$m_{\text {group I }}$} & \multirow[b]{2}{*}{$t$} & \multirow[b]{2}{*}{$N e_{\text {group II }}$} & \multirow[b]{2}{*}{$N e_{\text {group I }}$} & \multirow[b]{2}{*}{$N e_{\mathrm{A}}$} & \multicolumn{2}{|l|}{$N e_{(f)} m$} & \multirow[b]{2}{*}{$T$ (years) } \\
\hline & & & & & & & & & & group II to group I & group I to group II & \\
\hline MLE & 7.98 & 5.74 & 0.01 & 0.256 & 0.161 & 1.494 & 78,854 & 56,719 & 99 & 0.231 & 0.511 & 295,257 \\
\hline Lower HPD & 2.70 & 2.24 & 0.01 & 0.004 & 0.002 & 0.466 & 26,680 & 22,134 & 99 & 0.001 & 0.003 & 92,095 \\
\hline Upper HPD & 19.90 & 13.48 & 17.61 & 1.238 & 1.232 & 6.99 & 196,640 & 133,202 & 174,012 & 4.152 & 6.159 & $1,381,423$ \\
\hline
\end{tabular}

Population parameters that are scaled to the neutral mutation rate: $\theta_{\text {group II }} \theta_{\text {group I }}$ and $\theta_{\mathrm{A}}$ (effective number of individuals in group II, group I and ancestral population, respectively), $m_{\text {group II }}$ and $m_{\text {group I }}$ (the effective number of migrants per generation from group II to group I and from group I to group II, respectively), $t$ (time of population divergence); and respective demographic quantities after conversions: $N e_{\text {group II }}, N e_{\text {group I }}$ and $N e_{\mathrm{A}}$ (effective number of individuals in group II, group I and ancestral population, respectively), $N e_{(f)} m_{\text {group II-group I }}$ and $N e_{(f)} m_{\text {group I-group II }}$ (the effective number of migrants per generation from group II to group I and from group I to group II, respectively), $T$ (time of population splitting).

The time of populations splitting estimated between these two $A$. aestiva groups was 295,257 year $\mathrm{BP}$, corresponding approximately to the Middle Pleistocene, and TMRCA was 472,134 year вP $(\mathrm{T}=2.389)$.

\section{DISCUSSION}

\section{Phylogeographical pattern of $\boldsymbol{A}$. aestiva}

The molecular analysis of $A$. aestiva showed that the two main genetic groups identified in our analyses agree with the morphological variation, and corresponded to the geographical distributions of named subspecies: group I composed mainly of amazons from north-eastern localities BA, MG, TO, DF and GO, corresponding to the recognized geographical distribution of $A$. a. aestiva (Fig. 1); group II composed of individuals from south-western localities (MS, AR1 and AR2), corresponding to the distribution of A. a. xanthopteryx. The genetic differentiation between these groups was high as estimated by the hierarchical analysis of nucleotide diversity (Fig. 3).

Our results also suggested that MS area represents the ancestral distribution of this species and the two genetic groups identified in this study resulted from a recent population expansion to the Northeast and to the Southwest. Several studies suggest that higher levels of nucleotide diversity are indicative of population ancestry (Hewitt, 2000, 2004; Zink et al., 2000; Cheviron et al., 2005). MS showed higher nucleotide and haplotype diversities than the other populations (Table 1). Both, the distribution pattern of A. aestiva haplotypes in the network (Fig. 2) and the demographic analysis (Table 2; Fig. 4) provided evidence that the two $A$. aestiva genetic groups have undergone a recent population expansion, with low gene flow between them. The low gene flow between north-eastern and south-western populations might be contributed for morphological differences in shoulder colour between two A. aestiva subspecies.

Based on coalescence analysis, the time of population splitting estimated between the two $A$. aestiva groups was around 295,257 year вр (Table 2), corresponding to the Middle Pleistocene. Considering that the blue-fronted amazon occurs in relatively dry and open habitats, including Cerrado and Chaco, climate changes during this period, especially the expansion of savannah areas, may have contributed to the population expansion of these two genetic groups. The Quaternary history of South America is poorly known, although the fossil record is improving rapidly. In 
general, there is evidence that since 150,000 year BP several cycles of the general glacial-age pattern of colder and more arid conditions intercalated with warm, moist periods on the continent. These climate changes influenced the vegetation distribution, especially the Amazonian forest and savannah extension limits. At least part of the tropical rain forest experience a dynamic history as a result of precipitation change, temperature change (Bush \& Colinvaux, 1990; Colinvaux, 1996) and river dynamics (Salo et al., 1986; Salo, 1987; Puhakka et al., 1992; Rasanen et al., 1995). The limited palaeoecological data from the lowlands of the Amazon Basin have been interpreted as severe aridity in the lowland tropics at the last glacial maximum (around 18,000 year BP; Martinson et al., 1987) resulting in widespread expansion of savannah (Behling \& Hooghiemstra, 2001) and fragmentation of rain forest (Haberle, 1997). Nevertheless, as an ice-age mostly lasts for some 60,000 year вр or more and is characterized by very unstable climatic conditions (Hooghiemstra et al., 1992; Behling \& Hooghiemstra, 2001) it is possible that the divergence and the expansion of the two A. aestiva groups identified in this work are correlated with savannah expansion.

\section{Evolutionary relationship between $A$. aestiva and A. ochrocephala}

Median-joining network recovered the division of the A. aestiva and A. ochrocephala complex into three primary clades (NSA, CA and SA) or lineages as previously described (Eberhard \& Bermingham, 2004; Ribas et al., 2007). Our results also corroborated that $A$. ochrocephala subspecies of the SA clade do not correspond to the current recognized taxonomy (based mainly on plumage colour) and that these subspecies comprise a polyphyletic group with $A$. aestiva as suggested in previous studies (Eberhard \& Bermingham, 2004; Russello \& Amato, 2004; Ribas et al., 2007). However, neither of these studies included sufficient samples of A. aestiva to detect historical or demographic events that may have influenced this complex pattern. The first two studies analysed only a few sample of A. aestiva without information of its geographical origin, and the latter also analysed few samples from only three regions of Brazil (Ribas et al., 2007).

The species-level polyphyly involving South American A. ochrocephala subspecies and A. aestiva may be explained by any of three alternative hypotheses: (1) the two nominal species actually represent geographical variants (races or subspecies) of a single species that continue to exchange genes; (2) there is incomplete lineage sorting between two distinct species; or (3) there has been introgression of genes as a result of hybridization. The observed phenotypic divergence between A. aestiva and $A$. ochrocephala may be either environmentally induced, or genetically based and maintained by strong selection despite of high gene flow. Considering that these two species are mostly allopatric, with just a small region of sympatry in western Brazil and north-eastern Bolivia (see Fig. 1), and occur in different habitats formations, the hypothesis of high level of gene flow between two geographical variants seems to be unlikely.
Alternatively, demographic processes such as incomplete lineage sorting of mtDNA lineages from a polymorphic ancestral gene pool or the introgression of genes as a result of interspecific gene flow may better explain our results. It is not possible to distinguish unequivocally between these two demographic processes, because both would lead to similar patterns of mtDNA haplotype distribution. However, haplotype sharing and network analysis provide support for the introgression hypothesis. A. aestiva from the north-eastern group are closely related and share haplotypes with A. o. xantholaema, and A. aestiva from the south-western group are closely related and share haplotypes with A. o. nattereri and A. o. ochrocephala from PA (see Figs 1 and 2). In the case of incomplete lineage sorting, A. aestiva groups should have maintained exactly the same pattern of haplotype distribution found in A. ochrocephala subspecies during the population expansion events. We consider this process unlikely, and concluded that introgression after isolated diversification may better explain haplotype sharing between these two species. Introgression is also supported by Eberhard \& Bermingham (2004) based on nuclear gene phylogeny. Although this work includes just one A. aestiva and four A. ochrocephala individuals, the results provide evidences for the monophyly of $A$. ochrocephala with respect to $A$. aestiva (i.e. evidence against paraphyly), suggesting introgression of mitochondrial genes. However, Russello \& Amato (2004) provide evidences of paraphyly based on both mitochondrial and nuclear gene sequences, even when only nuclear sequences were analysed.

Considering that the divergence between the two A. aestiva genetic groups (or subspecies) occurred in the Middle Pleistocene (as discussed previously), the secondary contact among $A$. aestiva and different subspecies of $A$. ochrocephala probably occurred recently, perhaps influenced by climate changes and the cycles of expansion and contraction of the savannah areas in the last 300,000 year вр. Natural hybridization and introgression are well-documented phenomena in many bird species especially in contact zones, and viable hybrid offspring has been recorded in $10 \%$ of bird species (Randler, 2004).

In relation to SA lineages, Eberhard \& Bermingham (2004) proposed two possible taxonomic arrangements for $A$. ochrocephala: (1) to recognize two species, A. ochrocephala, including ochrocephala from northern South America (corresponding to the NSA lineage), and A. nattereri, including ochrocephala from Amazonia, nattereri and xantholaema; or (2) to recognize only one species in South America, A. ochrocephala. Our data corroborate the Ribas et al. (2007) findings and indicated that A. ochrocephala from Colombia and Venezuela (corresponding to the NSA lineage) could be a separate species, A. ochrocephala, but the limits of its geographical distribution remain to be determined. However, inconclusive results were obtained for A. ochrocephala subspecies of the SA lineage; additional morphological and genetic studies involving more A. ochrocephala samples from different localities of Amazonia and especially samples from recognized contact zone between the South America A. ochrocephala subspecies are needed to answer these questions and to better understand the variation in plumage patterns that diagnose A. ochrocephala subspecies. 


\section{Conservation implications}

The rapid and intense destruction and fragmentation of natural habitats as a result of increased human activities have been progressively destroying the natural habitat of $A$. aestiva and $A$. ochrocephala, contributing effectively to the reduction of wild population size (Bucher \& Martella, 1988; Collar \& Juniper, 1988). Additionally, the capture of wild individuals for the pet trade may have seriously affected wild population size, especially A. aestiva. Although these species are not considered threatened by IUCN and Brazilian official institutions responsible for biodiversity conservation, the scenario of progressive population decline and fragmentation indicates the need for conservation efforts.

During the last three decades, the identification of genetically distinct populations has been a key issue on conservation biology (Wayne, 1992; Paetkau, 1999; Frankham et al., 2002). The relevance of these concepts and the genetic information in species conservation, including data on population structure, has been widely recognized (Paetkau, 1999; Eizirik et al., 2001; Coulon et al., 2006; Dethmers et al., 2006) to develop adequate conservation and management strategies.

Despite the taxonomic problems concerning A. aestiva and the A. ochrocephala complex, we suggest that management and conservation strategies should consider the genetically and phenotypically different groups (or subspecies) as different management units (MU) and should maintain viable populations of these two MUs. Regarding the South America A. ochrocephala subspecies, population genetic analyses are needed to determine the geographical limits of MUs and provide information for conservation purposes.

\section{ACKNOWLEDGEMENTS}

We thank all students from the Molecular Ecology and Conservation Genetics group of the Universidade Católica de Brasília for their kind help in field and laboratory work, and the support of the Brazilian Institute for the Environment (IBAMA) and the staff of the National Park of Emas, National Park of Grande Sertão Veredas and Jardim Zoológico de Brasília during the field work. We also acknowledge E. Leornadecz-Neto for the kind help in coalescent analyses, and L. F. Silveira, R. A. Nichols and M. Patten for helpful comments on this manuscript. Jon Paul Rodriguez and two anonymous reviewers provide valuable suggestions to improve the manuscript. This work was supported by Conselho Nacional de Desenvolvimento Científico e Tecnológico $(\mathrm{CNPq})$ and Universidade Católica de Brasília, whose assistance we gratefully acknowledge.

\section{REFERENCES}

Avise, J.C. (2000) Phylogeography: the history and formation of species. Harvard University Press, Cambridge, MA.

Avise, J.C. \& Walker, D. (1998) Pleistocene phylogeography effects on avian populations and the speciation process. Proceedings of the Royal Society of London Series B: Biological Sciences, 265, 457-463.
Bandelt, H.J., Forster, P. \& Röhl, A. (1999) Median-joining networks for inferring intraspecific phylogenies. Molecular Biology and Evolution, 16, 37-48.

Behling, H. \& Hooghiemstra, H. (2001) Neotropical savannah environments in space and time: late quaternary interhemispheric comparisons. Interhemispheric climate linkages (ed. by V. Markgraf), pp. 307-323. Academic Press, New York.

Brown, W.M., George, M. \& Wilson, A.C. (1979) Rapid evolution of animal mitochondrial DNA. Proceedings of the National Academy of Sciences USA, 76, 1967-1971.

Bruford, M.W., Hanotte, O., Brokfield, J.F.Y. \& Burke, T. (1992) Single-locus and multilocus DNA fingerprinting. Molecular genetic analysis of populations: a practical approach (ed. by A.R. Hoelzel), pp. 225-269. IRL Press, Oxford.

Bucher, E.H. \& Martella, M.B. (1988) Preliminary report on the current status of Amazona aestiva in the Western Chaco, Argentina. ICBO Parrotletter, 1, 9-10.

Bush, M.B. \& Colinvaux, P.A. (1990) A pollen record of a complete glacial cycle in lowland Panama. Journal of Vegetation Science, 1, 105-118.

Cheviron, Z.A., Hackett, S.J. \& Capparella, A.P. (2005) Complex evolutionary history of a Neotropical lowland forest bird (Lepidothrix coronata) and its implications for historical hypotheses of the origin of Neotropical avian diversity. Molecular Phylogenetics and Evolution, 36, 338-357.

Colinvaux, P.A. (1996) Low-down on a land bridge. Nature, 382, 21-23.

Collar, N.J. (1997) Family Psittacidae (parrots). Handbook of the birds of the world (sandgrouse to coockos), vol. 4 (ed. by J. Del Hoyo, A. Elliott, J. Sargatal and J. Cabot), pp. 280-477. Lynx Edicions, Barcelona.

Collar, N.J. \& Juniper, A.T. (1988) Dimensions and causes of the parrot conservation crisis. New world parrot in crisis: solutions from conservation biology (ed. by S.R. Beissinger and N.F.R. Snyder), pp. 3-21. Smithsonian Institution Press, Washington.

Coulon, A., Guillot, G., Cosson, J.-F., Angibault, J.M.A., Aulagnier, S., Carnelutti, B., Galan, M. \& Hewison, A.J.M. (2006) Genetic structure is influenced by landscape features: empirical evidence from a roe deer population. Molecular Ecology, 15, 1669-1679.

Darrieu, C.A. (1983) Revision de las razas geograficas de Amazona aestiva (linne), (Aves, Psittacidae). Neotropica, 29, 3-10.

Dethmers, K.E.M., Broderick, D., Moritz, C., Fitzsimmons, N.N., Limpus, C.J., Lavery, S., Whitinh, S., Guinea, M., Prince, R.I.T. \& Kemmett, R. (2006) The genetic structure of Australasian green turtles (Cheloniamydas): exploring the geographical scale of genetic exchange. Molecular Ecology, 15, 39313946.

Eberhard, J.R. \& Bermingham, E. (2004) Phylogeny and biogeography of the Amazona ochrocephala (Aves: Psittacidae) complex. The Auk, 121, 318-332.

Eizirik, E., Kim, J.H., Menotti-Raymond, M., Crawshaw, P.G., O’Brien, S.J. \& Johnson, W.E. (2001) Phylogeography, 
population history and conservation genetics of jaguars (Panthera onca, Mammalia, Felidae). Molecular Ecology, 10, 65-79.

Forshaw, J.M. (1989) The parrots of the world, 3rd ed, Lansdowne Press, Willoughby.

Frankham, R., Ballou, J.D. \& Briscoe, D.A. (2002) Resolving taxonomic uncertainties and defining management units. Introduction to conservation genetics (ed. by R. Frankham, J.D. Ballou and D.A. Briscoe), pp. 365-394. Cambridge University Press, New York.

Fu, Y.-X. (1997) Statistical tests of neutrality of mutations against population growth, hitchhiking and background selection. Genetics, 147, 915-925.

Haberle, S.G. (1997) Upper Quaternary vegetation and climate history of the Amazon basin: correlating marine and terrestrial pollen records. Proceedings of the ocean drilling program, scientific results, vol. 155 (ed. by R.D. Flood, D.J.W. Piper, A. Klaus and L.C. Peterson), pp. 381-396. Ocean Drilling Program, Texas.

Hewitt, G. (2000) The genetic legacy of the Quaternary ice ages. Nature, 405, 907-913.

Hewitt, G. (2004) Genetic consequences of climatic oscillations in the Quaternary. Philosophical Transactions of the Royal Society of London Series B: Biological Sciences, 359, 183195.

Hey, J. \& Nielsen, R. (2004) Multilocus methods for estimating population sizes, migration rates and divergence time, with applications to the divergence of Drosophila pseudoobscura and D. persimilis. Genetics, 167, 747-760.

Holsinger, K.E. \& Mason-Gamer, R.J. (1996) Hierarchical analysis of nucleotide diversity in geographically structured populations. Genetics, 142, 629-639.

Hooghiemstra, H., Clef, A.M., Noldus, G.W. \& Kapelle, M. (1992) Upper Quaternary vegetation dynamics and palaeoclimatology of the La Chonta bog area, Costa Rica. Journal of Quaternary Science, 7, 205-225.

IUCN (2006) 2006 IUCN red list of threatened species. Available at $<$ http://www.iucnredlist.org $>$.

Juniper, T. \& Parr, M. (1998) Parrots: a guide to parrots of the world. Yale University Press, New Haven.

Martinson, D.G., Pisias, N.G., Hays, J.D., Imbrie, J., Moore, T.C. Jr \& Shackleton, N.J. (1987) Age dating and the orbital theory of ice ages: development of a high-resolution 0 to 300,000 years chronostratigraphy. Quaternary Research, 27, 1-29.

Nei, M. (1987) Molecular evolutionary genetics. Columbia University Press, New York.

Newton, I. (2003) The speciation and biogeography of birds. Academic Press, San Diego.

Paetkau, D. (1999) Using genetics to identify intraspecific conservation units: a critique of current methods. Conservation Biology, 13, 1507-1509.

Palumbi, S.R. (1996) Nucleic acids II: The polymerase chain reaction. Molecular systematics (ed. by D.M. Hillis, D.M. Moritz and B.K. Mable), pp. 205-247. Sinauer Associates, Sunderland.
Potts, R. \& Behrensmeyer, A.K. (1992) Late Cenozoic terrestrial ecosystems. Terrestrial ecosystems through time: evolutionary paleoecology of terrestrial plants and animals (ed. by A.K. Behrensmeyer, J.D. Damuth, W.A. DiMichele, R. Potts, H.-D. Sues and S.L. Wing), pp. 419-541. University of Chicago Press, Chicago.

Puhakka, M., Kalliola, R., Rajasilta, M. \& Salo, J. (1992) River types, site evolution and sucessional vegetation patterns in Peruvian Amazonia. Journal of Biogeography, 19, 651-665.

Ramos-Onsins, S.E. \& Rozas, J. (2002) Statistical properties of new neutrality tests against population growth. Molecular Biology and Evolution, 19, 2092-2100.

Randi, E. (1996) A mitochondrial cytochrome $b$ phylogeny of the Alectoris partridges. Molecular Phylogenetics and Evolution, 6, 214-227.

Randler, C. (2004) Frequency of bird hybrids: does delectability make all the difference? Journal of Ornithology, 145, 123128.

Rasanen, M.E., Linna, A.M., Santos, J.C. \& Negri, F.R. (1995) Late Miocene tidal deposits in the Amazonian foreland basin. Science, 269, 386-390.

Ribas, C.C., Tavares, E.S., Yoshihara, C. \& Miyaki, C.Y. (2007) Phylogeny and biogeography of yellow-headed and blue fronted parrots (Amazona ochrocephala and Amazona aestiva) with reference to the South American taxa. Ibis, 149, 564-574.

Rogers, A.R. \& Harpending, H. (1992) Population growth makes waves in the distribution of pairwise genetic differences. Molecular Biology and Evolution, 9, 552-569.

Rozas, J., Sánchez-De I., Barrio, J.C., Messeguer, X. \& Rozas, R. (2003) DnaSP, DNA polymorphism analyses by the coalescent and other methods. Bioinformatics, 19, 2496-2497.

Russello, M. \& Amato, G. (2004) A molecular phylogeny of Amazona: implications for Neotropical parrot biogeography, taxonomy, and conservation. Molecular Phylogenetics and Evolution, 30, 421-437.

Salo, J. (1987) Pleistocene forest refuges in the Amazon: evaluation of the biostratigraphical, lithostratigraphical and geomorphical data. Annales Zoologici Fennici, 24, 203-211.

Salo, J., Kalliola, R., Häkkinen, I., Mäkinen, Y., Niemelä, P., Puhakka, M. \& Coley, P.D. (1986) River dynamics and the diversity of Amazon lowland forest. Nature, 322, 254258.

Schneider, S., Roessli, D. \& Excoffier, L. (2000) ARLEQUIN. A software for population genetics data analysis, ver 2000, Genetics and Biometry Laboratory, Department of Anthropology and Ecology, University of Geneva, Switzerland.

Shields, G.F. \& Wilson, A.C. (1987) Calibration of mitochondrial DNA evolution in geese. Journal of Molecular Evolution, 24, 212-217.

Thompson, J.D., Gibson, T.J., Plewniak, F., Jeanmougin, F. \& Higgins, D.G. (1997) The ClustalX windows interface: flexible strategies for multiple sequence alignment aided by quality analysis tools. Nucleic Acids Research, 25, 48764882 . 


\section{R. Caparroz et al.}

Wayne, R.K. (1992) On the use of morphologic and molecular genetic characters to investigate species status. Conservation Biology, 6, 590-592.

Wilson, A.C., Cann, R.L., Carr, S.M., George, M., JrGyllensten, U.B., Helm-Bychowski, K., Higuchi, R.G., Palumbi, S.R., Prager, E.M., Sage, R.D. \& Stoneking, M. (1985) Mitochondrial DNA and two perspectives on evolutionary genetics. Biological Journal of the Linnean Society, 26, 375-400.

Zink, R.M., Barrowclough, G.F., Atwood, J.L. \& Blackwell-Rago, R.C. (2000) Genetics, taxonomy, and conservation of the threatened California Gnatcatcher. Conservation Biology, 14, 1394-1405.

Editor: Jon Paul Rodriguez

\section{SUPPORTING INFORMATION}

Additional Supporting Information may be found in the online version of this article:

Appendix S1 Taxa sampled, locality, codes of the locality within South America, voucher numbers, Amazona aestiva haplotype number and GenBank accession numbers.

Please note: Wiley-Blackwell are not responsible for the content or functionality of any supporting materials supplied by the authors. Any queries (other than missing material) should be directed to the corresponding author for the article. 